\title{
Short communication: Calf body temperature following chemical disbudding with sedation: Effects of milk allowance and supplemental heat
}

\author{
E. Vasseur, ${ }^{1,2}$ J. Rushen, and A. M. de Passillé \\ Pacific Agri-Food Research Centre, Agriculture and Agri-Food Canada, Agassiz, British Columbia, Canada, V0M 1A0
}

\begin{abstract}
The use of caustic paste combined with a sedative is one of the least painful methods for disbudding. It is recommended to disbud at as early as $5 \mathrm{~d}$ of age. However, the sedative xylazine reportedly causes a decrease in core temperature. Furthermore, young calves do not thermoregulate efficiently. We investigated the effects of disbudding calves at $5 \mathrm{~d}$ of age using caustic paste and xylazine sedation on body temperature, activity, and milk intake of 46 individually housed 5-d-old calves in a $2 \times 2$ factorial design, with milk fed at $4.5 \mathrm{~L} / \mathrm{d}$ (low-fed calves) versus $9 \mathrm{~L} / \mathrm{d}$ (high-fed calves), with or without a heat lamp. Body temperature, calf activity (standing time), and barn temperature were monitored continuously using automatic data loggers on the day of, before the day of, and the day after disbudding. All calves were injected intramuscularly with $0.25 \mathrm{~mL}$ of 2 $\mathrm{mg} / \mathrm{mL}$ xylazine $20 \mathrm{~min}$ before disbudding (dose: 0.12 $\pm 0.003 \mathrm{~mL} / \mathrm{kg}$ of BW). We found that the body temperature of 5-d-old calves decreased immediately after the injection of the sedative xylazine. The body temperature of calves decreased $0.9 \pm 0.09^{\circ} \mathrm{C}$ and it took $3.8 \pm 0.32 \mathrm{~h}$ to climb back to the preinjection body temperature. Calves that were fed the lower amount of milk, received a higher dose of xylazine $(\mathrm{mL} / \mathrm{kg} \mathrm{BW})$, or were disbudded in a colder environment were more affected by body temperature variations (lower and longest decrease in body temperature and higher magnitude). Calf activity recovery followed the pattern of body temperature recovery. Milk allowance and supplemental heat did not help enhance recovery during the $6 \mathrm{~h}$ following the procedure. The disbudding procedure did not affect milk intake but calves with less body temperature decrease or kept in a warmer environment drank more milk following disbudding. Low-fed calves were overall more affected by the procedure than highfed calves during the disbudding day and the following
\end{abstract}

Received September 23, 2013.

Accepted May 5, 2014.

${ }^{1}$ Current address: Organic Dairy Research Center, University of Guelph-Campus d'Alfred, Alfred, Ontario, Canada, K0B 1A0.

${ }^{2}$ Corresponding author: vasseur.elsa@gmail.com day (greater decrease in body temperature and drank less in the colder environment). Providing a high-milk diet is a suitable option to help mitigate calf discomfort due to the disbudding procedure, whereas using a heat lamp does not seem to help, at least in a mildly cold winter.

Key words: body temperature, calf, chemical disbudding, sedative xylazine

\section{Short Communication}

Dairy producers dehorn or disbud their cattle for the safety of the animals and their caregivers but these procedures have proved to be both stressful and painful for cattle. Disbudding before 3 wk of age is recommended (e.g., National Farm Animal Care Council, 2009) and the use of caustic paste combined with a sedative is one of the least painful methods for horn bud removal (Vickers et al., 2005; Stilwell et al., 2009). Calves can be disbudded using caustic paste with sedation, typically xylazine, as early as $5 \mathrm{~d}$ of age. However, xylazine has been associated with decreases in body temperature in cats and dogs (Sinclair, 2003) but the effect of xylazine on body temperature of very young calves has not been studied. The use of xylazine may be a problem for young calves that may have difficulties thermoregulating (Piccione et al., 2003). Furthermore, calves are born with limited body energy reserves and modest insulation afforded by their hair coat and body fat. Borderas et al. (2009) demonstrated that calves had a strong preference to be under an infrared heat lamp (HL) and Uystepruyst et al. (2002) showed that calves under an HL maintain higher body temperature without increasing energy mobilization. These results suggest that a HL may be a good option to improve calf thermal comfort when challenged. Alternatively, Schrama et al. (1992) reported that calves fed low quantities of milk exhibited decreased heat production, probably due to exhaustion of body reserves, suggesting that giving high quantities of milk may be another option to improve calf thermal comfort when challenged. The objective of this study was to examine if disbudding with caustic paste and xylazine sedation of 5-d-old calves would cause a body temperature decrease and if feeding 
high quantities of milk or providing a heat supply, or both, could help the calf maintain its body temperature and improve its recovery from disbudding, as shown by its activity level and milk intake.

The study was conducted on 41 female and 5 male Holstein calves (birth weight: $42.1 \pm 0.77 \mathrm{~kg}$ ) from the University of British Columbia Dairy Education and Research Center (Agassiz, British Columbia, Canada) from November 2009 to March 2010. Soon after birth, calves were bottle-fed $4 \mathrm{~L}$ of colostrum and moved from a calving pen to individual pens $(2.0 \times 1.1 \mathrm{~m}$; sawdust on concrete) where they remained for $7 \mathrm{~d}$. At $1 \mathrm{~d}$ of age, calves were assigned to 1 of 4 treatments, balancing for weight at birth, in a $2 \times 2$ design: milk fed with $4.5 \mathrm{~L} / \mathrm{d}$ (low-fed calves) or $9 \mathrm{~L} / \mathrm{d}$ (high-fed calves) and housed with or without an HL. The HL (Satco indoor Red 250W S4998; Satco Products Inc., Brentwood, NY; fixed in the middle of the pen, at $0.9 \mathrm{~m}$ of height) was provided from the time of the first milk meal. Using a black globe thermometer (model 210-4417; NovaLynx Corp., Grass Valley, CA), the lamps were found to provide heat so that a temperature of $28^{\circ} \mathrm{C}$ was recorded at the average height of the calf's back (Vasseur et al., 2009). The ambient temperature of the calf barn was recorded every $5 \mathrm{~min}$ using a climatic data logger (HOBO ProV2 Temp/RH; Onset Computer Corp., Bourne, MA) and was averaged for each week a calf had been disbudded [barn temperature: $7.4 \pm 0.34^{\circ} \mathrm{C}$ $\left(\right.$ minimum $=1.7 ;$ maximum $\left.\left.=11.1^{\circ} \mathrm{C}\right) ; \mathrm{n}=46\right]$.

Calves were disbudded at $5 \mathrm{~d}$ of age in their pen $1 \mathrm{~h}$ after the a.m. milk delivery following the procedure of Vickers et al. (2005), with the exception that the sedative xylazine (Rompun, $2 \mathrm{mg} / \mathrm{mL}$; Bayer Inc., Sarnia, Ontario, Canada) was not adjusted to BW and injected intramuscularly at $0.25 \mathrm{~mL} 20 \mathrm{~min}$ before application of the caustic paste (dose: $0.12 \pm 0.003 \mathrm{~mL} / \mathrm{kg}$ of BW; $\mathrm{n}=40$ calves). Once the sedation took effect and the animal was lying sternally, the hair surrounding each horn bud was trimmed with clippers. A thin film of caustic paste (Dr. Naylor Dehorning Paste; H. W. Naylor Company Inc., Morris, NY), approximately $2 \mathrm{~cm}$ in diameter, was rubbed on the scalp, covering the buds until they were evenly coated.

Disbudding day is referred to as $\mathrm{d} 0, \mathrm{~d}-1$ as the day before disbudding day, and $\mathrm{d}+1$ as the day following the disbudding day. Each day $(24 \mathrm{~h})$ started at first milk delivery $(0800 \mathrm{~h})$ of the day and ended just before the first milk delivery of the following day $(0800 \mathrm{~h})$.

\section{Body Temperature}

The body temperature of each calf was recorded continuously (every $10 \mathrm{~min}$ ) using a temperature logger (DS1921H/Z Thermochron iButton; Dallas Semicon- ductor, Dallas, TX) inserted into the vaginal cavity at $1 \mathrm{~d}$ of age $(\mathrm{n}=40$ calves). Temperature loggers (1.6 $\times 0.6 \mathrm{~cm}$ ) were wrapped in a latex pouch and a bead was attached to the pouch with fishing line to facilitate insertion and removal. By the time that disbudding was performed, calves had reached stable body temperature (vaginal temperature: $38.6 \pm 0.1^{\circ} \mathrm{C}$; Vasseur et al., 2010b).

To examine the effect of the disbudding procedure on body temperature, daily minimum temperature variations between days $(\mathrm{d}-1$ to $\mathrm{d} 0$ and $\mathrm{d}-1$ to $\mathrm{d}+1$ ) were tested using the mixed model (PROC MIXED) procedure of SAS (version 9.2; SAS Institute Inc., Cary, NY), with fixed effects of treatment, day, and interactions of treatment with day, controlling for repeated measures of day. On d 0, we calculated for each calf 3 variables of body temperature variations: the magnitude and duration of the decrease in body temperature after injection (disbudding) and the minimum temperature at the decrease. A decrease in temperature started when the temperature decreased below the preinjection temperature (average of 12 recordings) and ended when the temperature climbed back up to the preinjection body temperature. The duration of the decrease was the difference between the start time and end time. The magnitude of the decrease was the difference in degrees Celsius between the preinjection and minimum temperature at the decrease. General linear models were used to analyze the factor effects of diet and HL and interactions of diet with HL on body temperature variation variables (PROC GLM). Because we did not adjust the quantity of xylazine for the calf weight, we tested the effect of dose received $(\mathrm{mL} / \mathrm{kg}$ of $\mathrm{BW})$ on body temperature variation variables using simple linear regression analysis (PROC GLM). The same procedure was repeated to test the effect of the barn temperature on body temperature variation variables. Dependent variables were tested for normality using the Shapiro-Wilk test (PROC UNIVARIATE).

The disbudding procedure had an effect on vaginal temperature: the daily minimum temperature decreased $\left(-0.6 \pm 0.02^{\circ} \mathrm{C} ; P<0.0001\right)$ between $\mathrm{d}-1$ and 0 , but not between $\mathrm{d}-1$ and $+1(P>0.1)$. No effect of treatment $(P>0.1)$ or interaction treatment with day $(P>0.1)$ was found on daily minimum temperature. However, considerable variation existed between calves. This variation was related to the dose received by the calves and the external temperature. Indeed, the higher the dose injected $(\mathrm{mL} / \mathrm{kg}$ of $\mathrm{BW})$, the lower the minimum temperature at the decrease $(\mathrm{r}=-0.3 ; P=$ 0.03 ) and the greater the magnitude of the temperature at the decrease $(\mathrm{r}=0.5 ; P=0.003)$, but dose was not associated with the duration of the decrease $(P$ $>0.1)$. However, even when significant, associations 
between dose and vaginal temperature were low. The barn temperature was positively associated with minimum temperature at the decrease $(\mathrm{r}=0.5 ; P=0.002)$, and negatively associated with the magnitude of the temperature decrease $(\mathrm{r}=-0.6 ; P<0.0001)$ and the duration of the decrease $(\mathrm{r}=-0.4 ; P=0.007)$.

The size of the decrease in temperature was affected by milk allowance. The minimum body temperature of high-fed calves at the time of the decrease was higher $\left(+0.4 \pm 0.01^{\circ} \mathrm{C}\right)$ and the magnitude of the decrease was smaller $\left(0.3 \pm 0.00^{\circ} \mathrm{C}\right)$ than for low-fed calves (Table $1)$. No effect of milk intake on the duration of the decrease was observed. No effect of the HL was observed nor did an interaction exist between diet and HL on the minimum temperature at the decrease and on the magnitude and duration of the decrease in temperature after injection (Table 1).

All 3 variables of body temperature variation at the decrease were highly correlated (Pearson correlation coefficients; PROC CORR). The magnitude of the decrease in temperature after injection was negatively correlated with the minimum temperature at the decrease $(\mathrm{r}=-0.8 ; P<0.0001)$ and positively correlated with the duration of the decrease $(\mathrm{r}=0.8, P<0.0001)$. The magnitude of the decrease was, therefore, solely selected for further analysis because it best explained variations in body temperature after injection.

\section{Activity}

The position of each calf (lying or standing) was recorded continuously (every $1 \mathrm{~min}$ ) using an activity logger (HOBO Pendant G; Onset Computer Corp.) placed on a hind leg at $1 \mathrm{~d}$ of age, along the metatarsus bone located on the outer side of the leg, following the procedure of Bonk et al. (2013). To examine if our treatments would enhance activity recovery, on $\mathrm{d} 0$, the total time standing was calculated for each hour from injection (h 0 ) to $6 \mathrm{~h}$ after injection (h 6 ). To examine the effect of the disbudding procedure on activity, the total time standing was calculated for $24 \mathrm{~h}$ on $\mathrm{d}-1$, 0 , and +1 . Distribution of activity variables tended to be nonnormal; therefore, nonparametric analyses were used. Wilcoxon scores (sum of ranks; PROC NPAR1WAY) were used to analyze activity differences among treatments and Wilcoxon signed rank tests (PROC NPAR1WAY) were used to analyze activity variations between consecutive hours following the xylazine injection (h 0 to 1,1 to 2,2 to 3,3 to 4,4 to 5 , and 5 to 6 ) and between days (d -1 to 0 and $d-1$ to +1$)$. The Spearman rank correlation coefficient (PROC CORR) was calculated between dose as well as for magnitude of the decrease in temperature after injection, barn temperature, and duration of standing at every $6 \mathrm{~h}$ fol-

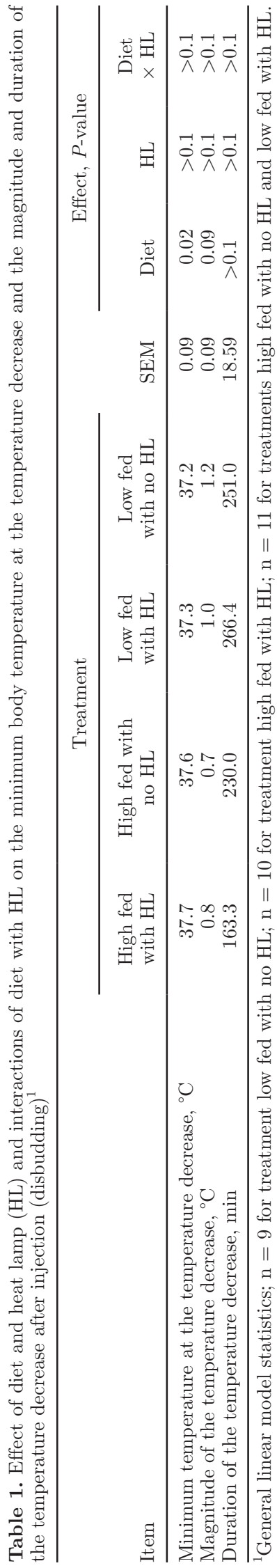

Journal of Dairy Science Vol. 97 No. 8, 2014 
lowing injection to evaluate the degree of association between activity and dose, decrease in body temperature, and barn temperature.

The disbudding procedure had little effect on daily activity. No significant differences were found between $\mathrm{d}-1$ and 0 in daily total time standing. Daily total standing time increased significantly between $\mathrm{d}-1$ and $+1(+75 \pm 9.0 \mathrm{~min} / \mathrm{d})$ for all treatments [range $(\mathbf{S})=$ -23.5 to $-39 ; P=0.01-0.0005]$, with the exception of low-fed calves with HL. No effect was observed of HL, milk intake, or an interaction between HL and milk intake on the duration of standing by the calves at any day.

Time spent standing between consecutive hours decreased between $\mathrm{h} 0$ and $1(-158 \pm 45.8 \mathrm{~min} ; \mathrm{S}=236$; $P=0.001)$, and increased between $\mathrm{h} 2$ and $3(+335$ $\pm 73.4 \mathrm{~min} ; \mathrm{S}=-261.5 ; P<0.0001)$ and $\mathrm{h} 4$ and 5 $(+452 \pm 181.2 \mathrm{~min} ; \mathrm{S}=-163.5 ; P=0.02)$. No effect of HL (range within hours; $P=0.07$ to $P>0.1$ ) and diet (range within hours; $P=0.06$ to $P>0.1$ ) was found on the duration of standing during the $6 \mathrm{~h}$ following disbudding. We found no association between the dose (range within hours; $\mathrm{r}=-0.3$ to $+0.1 ; P>0.1$ ) or barn temperature (range within hours; $\mathrm{r}=-0.2$ to +0.2 ; $P>0.1)$ on the duration of standing during the $6 \mathrm{~h}$ following disbudding. We found no association between the magnitude of the decrease in temperature following injection and the duration of standing during the $6 \mathrm{~h}$ following disbudding, with the exception of duration of standing during the fourth hour following injection (h $3 ; \mathrm{r}=0.3 ; P=0.03)$.

\section{Milk Intake}

Milk was available all day long from an individual milk bar feeder (McInnes Manufacturing Ltd., Waipu, New Zealand), unless the calf drank all of its milk allowance before the next feeding. Calves were fed a total of either 9 or $4.5 \mathrm{~L} / \mathrm{d}$ of pasteurized milk in 2 meals (at 0800 and $1500 \mathrm{~h}$ ) and leftover milk was weighed twice per day and discarded just before milk delivery.
By the time that disbudding was performed, calves no longer needed help to feed themselves and consumed freely more than $10 \% \mathrm{BW}$ in milk from the milk bar feeder (high fed: $6.5 \pm 0.3 \mathrm{~L} / \mathrm{d}$; low fed: $4.2 \pm 0.3 \mathrm{~L} / \mathrm{d}$; Vasseur et al., 2010b).

To examine if our treatments would enhance milk intake, milk intake was calculated at the 2 meals following disbudding: milk intake at the p.m. meal on $\mathrm{d}$ 0 and at the a.m. meal on $d+1$. To examine the effect of the disbudding procedure on milk intake, daily milk intakes at $\mathrm{d}-1,0$, and +1 were also calculated. Distribution of milk intake variables tended to be nonnormal; therefore, nonparametric analyses were used. Wilcoxon scores (sum of ranks; PROC NPAR1WAY) were used to analyze milk intake variations among treatments and Wilcoxon signed rank tests (PROC NPAR1WAY) were used to analyze milk intake variations between days (d -1 to 0 and $d-1$ to +1 ). The Spearman rank correlation coefficient (PROC CORR) was calculated between dose, magnitude of the decrease in temperature after injection, and barn temperature, and milk intake at the 2 meals following disbudding to evaluate the degree of association between milk intake and dose, decrease in body temperature, and barn temperature.

The disbudding procedure did not have an effect on daily milk intake (Table 2): no significant difference in milk intake was found between $\mathrm{d}-1$ and 0 either for low- $(\mathrm{S}=-56 ; P>0.1)$ or high-fed calves $(\mathrm{S}=+28 ; P$ $<0.1)$. A very small increase $(+0.2 \pm 0.03 \mathrm{~L})$ in milk intake was detected between $\mathrm{d}-1$ and +1 for low-fed calves only $(\mathrm{S}=-115 ; P<0.0001)$.

No association between the dose injected and milk intake was found at the 2 meals following disbudding $[\mathrm{r}=0.0(P>0.1)$ and $\mathrm{r}=-0.3(P>0.1)$ for the p.m. meal on $\mathrm{d} 0$ and the a.m. meal on $\mathrm{d}+1$, respectively]. The magnitude of the decrease in temperature following injection was negatively associated with milk intake for both meals following disbudding $[\mathrm{r}=-0.3(P=0.04)$ and $\mathrm{r}=-0.5(P=0.0007)$ for the p.m. meal on $\mathrm{d} 0$ and the a.m. meal on $d+1$, respectively]. Barn temperature was positively associated with milk intake for the first

Table 2. Effect of diet and heat lamp (HL) and interactions of diet with HL on daily milk intake prior to, during, and after disbudding day (d $-1,0$, and +1 , respectively) and on milk intake at the 2 next meals following disbudding (p.m. meal on $\mathrm{d} 0$ and a.m. meal on $\mathrm{d}+1)^{1}$

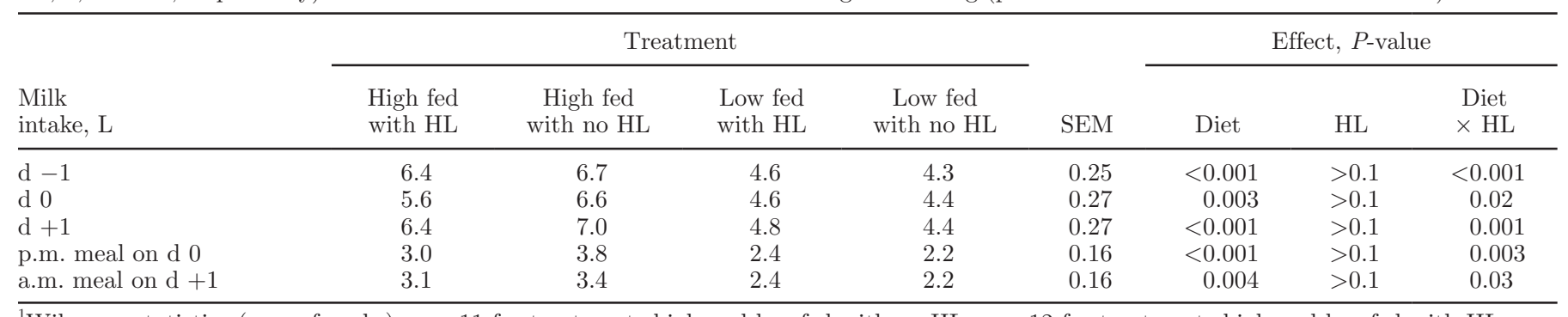

${ }^{1}$ Wilcoxon statistics (sum of ranks); $\mathrm{n}=11$ for treatments high and low fed with no HL; $\mathrm{n}=12$ for treatments high and low fed with HL. 
meal following injection $(\mathrm{r}=0.3 ; P=0.03)$ but not for the second meal $(\mathrm{r}=0.1 ; P>0.1)$.

Overall, we found that injection of the sedative xylazine with chemical disbudding reduced the body temperature of 5 -d-old calves by approximately $1^{\circ} \mathrm{C}$ and it took the calves $4 \mathrm{~h}$ to recover back to their initial body temperature (before injection); this variation in body temperature is far beyond what calves that age show in daily variation (Piccione et al., 2003). Slight reductions in temperature with animals sedated with $\alpha-2$ receptor agonists (drug type including xylazine) were observed in dogs, attributed to central nervous system depression in combination with a reduction in muscular activity (drugs: medetomidine and romifidine; Sinclair, 2003). Ruminants may have a greater sensitivity to the sedative effects of $\alpha-2$ receptor agonists because they have 2 types of $\alpha$-receptors in the brain stem (Sinclair, 2003). This specificity may induce higher central nervous system depression and may explain the greater reduction in body temperature observed in our calves than in dogs. However, large differences existed between calves in the extent of this reduction. The maximum decrease in temperature observed in our study was $2^{\circ} \mathrm{C}$ and the maximum duration of recovery was $8 \mathrm{~h}$ (reaching the temperature recorded before injection). However, onethird of our calves had a decrease in temperature of $0.5^{\circ} \mathrm{C}$ or less following injection. Some of this variation was due to the fact that we gave a standard dose, regardless of the calf's BW. Smaller calves that received a higher dose per kilogram of BW showed a bigger decrease in body temperature. However, even if significant, associations between dose and vaginal temperature were low. More research should be conducted to investigate further the effect of the dose on body temperature while disbudding using the sedative xylazine.

The decrease in temperature was also affected by the ambient temperature. Lower barn temperatures were associated with larger decreases in body temperature following injection. Our study was conducted under mild winter environmental conditions (average daily ambient temperature approximately $8^{\circ} \mathrm{C}$ ); the critical temperature for a calf of this age is $15^{\circ} \mathrm{C}(\mathrm{NRC}, 2001)$. However, we found no evidence that providing an $\mathrm{HL}$ mitigated the decrease in body temperature.

In contrast, the milk allowance of the calves had an effect. Providing more milk helped calves maintain a higher body temperature. Providing $10 \%$ of calf $\mathrm{BW}$ in milk is still a common practice in North American commercial dairies (Vasseur et al., 2010a). Calves 6 to $14 \mathrm{~d}$ of age show decreased heat production, probably due to a reduction in thyroid hormone level and the exhaustion of body reserves (Schrama et al., 1992). Our results prompt us to recommend giving extra milk to calves while disbudding in a cold environment to improve calf thermal comfort.

Calf activity recovery followed the pattern of body temperature, with a decrease in activity in the first hour following injection and then a progressive increase in the number of standing bouts and duration of standing in the fourth hour following injection. Diet and HL did not enhance activity recovery during the first $6 \mathrm{~h}$ following injection. No long-term negative effects of the disbudding procedure were observed on calf activity because calves do not stand less on the day following disbudding than on the previous day.

The disbudding procedure did not seem to negatively affect the daily milk intake in calves. Dose did not affect milk intake following disbudding. Interestingly, calves with a lesser body temperature decrease or kept in a warmer environment drank more milk following disbudding (small, but significant, associations). We showed earlier that calves kept in a warmer environment also had lesser decreases in body temperature. Those results suggest that calves less challenged to thermoregulate during disbudding are more likely to drink more milk. Although we did not find any significant effect of supplemental heat on milk intake or body temperature variations in mild weather, it may be of interest to investigate the potential advantages of providing an external source of heat to improve calf comfort when calves are disbudded during colder winter weather in a follow-up study.

Finally, high-fed calves drank more milk at both meals following disbudding, but they were already drinking more than low-fed calves on the previous day. Due to the confounding factors of diet on milk intake, these associations may simply confirm that low-fed calves exhibited other signs of coping less well with the disbudding procedure than high-fed calves (greater decreases in body temperature and drinking less in a colder environment). Therefore, providing a high-milk diet is a suitable option to help mitigate calf discomfort due to the disbudding procedure.

\section{ACKNOWLEDGMENTS}

We thank Agriculture and Agri-Food Canada (Ottawa, Ontario, Canada) and the Natural Sciences and Engineering Research Council of Canada (Ottawa, Ontario, Canada) for their financial support, Marine Legal (École National Vétérinaire de Toulouse, Toulouse France) for data handling and analysis, Marion Fleuret (AgroCampus Rennes, Rennes, France), Catherine Gagnon (Université de Sherbrooke, Sherbrooke, Québec, Canada), Lilianne Geerts and Jean-Philippe Parent (both from Agriculture and Agri-Food Canada, 
Agassiz, British Columbia, Canada) for technical assistance, and Nelson Dinn and the University of British Columbia Dairy and Educational Research Center staff (Agassiz, British Columbia, Canada) for help.

\section{REFERENCES}

Bonk, S., O. Burfeind, V. S. Suthar, and W. Heuwieser. 2013. Technical note: Evaluation of data loggers for measuring lying behavior in dairy calves. J. Dairy Sci. 96:3265-3271.

Borderas, F. T., A. M. B. de Passillé, and J. Rushen. 2009. Temperature preferences and feed level of the newborn dairy calf. Appl. Anim. Behav. Sci. 120:56-61.

National Farm Animal Care Council. 2009. Code of Practice for the Care and Handling of Dairy Cattle. Dairy Farmers of Canada, Ottawa, Ontario, Canada.

NRC. 2001. Nutrient Requirements of Dairy Cattle. 7th rev. ed. National Academy Press, Washington, DC.

Piccione, G., G. Caola, and R. Refinetti. 2003. Daily and estrous rhythmicity of body temperature in domestic cattle. BMC Physiol. 3:7.

Schrama, J. W., W. van der Hel, A. Arieli, and M. W. Verstegen. 1992. Alteration of energy metabolism of calves fed below maintenance during 6 to 14 days of age. J. Anim. Sci. 70:2527-2532.

Sinclair, M. D. 2003. A review of the physiological effects of $\alpha_{2}$-agonists related to the clinical use of medetomidine in small animal practice. Can. Vet. J. 44:885-897.
Stilwell, G., R. C. de Carvalho, M. S. Lima, and D. M. Broom. 2009 Effect of caustic paste disbudding, using local anaesthesia with and without analgesia, on behaviour and cortisol of calves. Appl. Anim. Behav. Sci. 116:35-44.

Uystepruyst, C., J. Coghe, T. H. Dorts, N. Harmegnies, M. H. Delsemme, T. Art, and P. Lekeux. 2002. Effect of three resuscitation procedures on respiratory and metabolic adaptation to extra uterine life in newborn calves. Vet. J. 163:30-44.

Vasseur, E., F. Borderas, R. I. Cue, D. Lefebvre, D. Pellerin, J. Rushen, K. M. Wade, and A. M. de Passillé. 2010a. A survey of dairy calf management practices in Canada that affect animal welfare. J. Dairy Sci. 93:1307-1315.

Vasseur, E., A. M. De Passillé, and J. Rushen. 2010b. Feeding behaviour and body temperature of newborn dairy calves in relation to feed level and heat supply. Page 201 in Proc. 44th Congress of the International Society for Applied Ethology (ISAE), Uppsala, Sweden. Wageningen Academic Publishers, Wageningen, the Netherlands.

Vasseur, E., J. Rushen, and A. M. de Passillé. 2009. Does a calf's motivation to ingest colostrum depend on time since birth, calf vigor, or provision of heat? J. Dairy Sci. 92:3915-3921.

Vickers, K. J., L. Niel, L. M. Kiehlbauch, and D. M. Weary. 2005. Calf response to caustic paste and hot-iron dehorning using sedation with and without local anesthetic. J. Dairy Sci. 88:1454-1459. 